\title{
Cross-cultural adaptation of Delphi definitions of low back pain prevalence in French (Delphi DOLBaPP-F)
}

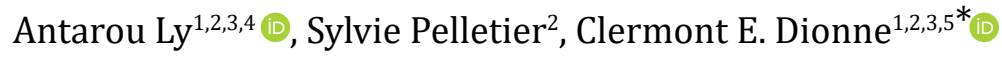 \\ ${ }^{1}$ Department of Social and Preventive Medicine, Université Laval, Quebec City, QC G1V 0A6, Canada \\ ${ }^{2}$ Centre de recherche du CHU de Quebec-Université Laval, Quebec City, QC G1S 4L8, Canada \\ ${ }^{3}$ Centre d'excellence sur le vieillissement de Quebec (CEVQ) du Centre de recherche en santé durable VITAM, Quebec City, QC \\ G1S 4L8, Canada \\ ${ }^{4}$ Institut de recherche en sciences de la santé (IRSS), 03 BP 7047 Ouagadougou 03, Burkina Faso \\ ${ }^{5}$ Department of Rehabilitation, Faculty of Medicine, Université Laval, QC City, Quebec G1V 0A6, Canada
}

*Correspondence: Clermont E. Dionne, Department of Social and Preventive Medicine, Université Laval, Quebec City, Quebec G1V 0A6, Canada. clermont.dionne@crchudequebec.ulaval.ca

Academic Editor: Emmanuel Lagarde, Bordeaux Population Health Research Center-U1219, Inserm, France

Received: July 18, 2021 Accepted: October 12, 2021 Published: December 31, 2021

Cite this article: Ly A, Pelletier S, Dionne CE. Cross-cultural adaptation of Delphi definitions of low back pain prevalence in French (Delphi DOLBaPP-F). Explor Med. 2021;2:483-93. https://doi.org/10.37349/emed.2021.00065

\begin{abstract}
Aim: The high heterogeneity in the definitions of low back pain encountered in the literature has led to the development of standardized definitions of this condition called "Delphi definitions of low back pain prevalence (Delphi DOLBaPP)" by a group of international researchers. In order to be widely used, these definitions need to be adapted according to the cultural and linguistic context. The aim of this work was to perform the cross-cultural adaptation of the Delphi DOLBaPP definitions in Quebec French and to pre-test them among French-speaking adults.

Methods: In order to enable practical use of the Delphi DOLBaPP definitions in different contexts, their presentation was adapted in the form of a questionnaire (referred to as the "Delphi DOLBaPP questionnaire"). The process of cross-cultural adaptation of the Delphi DOLBaPP questionnaire in French was conducted according to the most recognized recommendations for the cultural adaptation of measuring instruments. The resulting questionnaire and an evaluation form were then submitted to a sample of 82 adults.

Results: A total of 41 participants (50.0\%) reported low back pain. A high proportion of participants (89.0\%) stated that it took them less than 5 minutes to complete the questionnaire. More than $62.0 \%$ of them did not find any question poorly worded or confusing. Nearly $80.0 \%$ of the participants found the questionnaire easy to understand. The cross-cultural adaptation process suggested minor modifications to the original Delphi DOLBaPP questionnaire.

Conclusions: This study has produced a cross-cultural adaptation of the Delphi DOLBaPP questionnaire in Quebec French that will enable French-speaking populations to share the benefits of using standardized definitions of low back pain in epidemiological studies.
\end{abstract}




\section{Keywords}

Definition, low back pain, cross-cultural adaptation, prevalence

\section{Introduction}

Low back pain (LBP) is undoubtedly the most common musculoskeletal disorder in the world $[1,2]$. The average point prevalence of LBP is estimated at $18.3 \%$ and the one-month prevalence at $30.8 \%$ in the general population [3-5]. It is also estimated that $40-90 \%$ of adults will develop LBP during their lifetime [6, 7]. However, the estimation of the prevalence of LBP meets a major methodological limitation in the literature, due to the heterogeneity in the definition of cases $[3,8]$ : this makes it difficult to make valid comparisons and syntheses of frequency estimates. This difficulty can be observed in particular in systematic reviews on LBP $[3,4,9]$. To find solutions to this problem, 28 researchers from 12 countries worked in 2005-2006 to develop consensus definitions of LBP. As a result of this work, a "minimal" and an "optimal" definition of LBP were adopted by consensus and published [10]. These definitions were developed using the Delphi method [11-13] and were called "Delphi definitions of low back pain prevalence (Delphi DOLBaPP)". The "minimal" definition includes a question on the characteristics of pain (anatomical site, symptoms, and time of onset of symptoms) and a question on related functional limitations, and is recommended for use in large surveys where space and time are limited. The "optimal" definition includes five additional questions on frequency, duration of symptoms, intensity of pain and sciatica [10] and is more appropriate for studies specifically dealing with LBP. In order to enable practical use of these definitions in different contexts, their presentation was adapted in the form of questionnaires that could be self-administered or administered by an interviewer (referred to as the "Delphi DOLBaPP questionnaires"). These standardized definitions and the derived questionnaires have been developed in English and are suitable for use with English-speaking populations. However, the use of these definitions in languages other than English requires them to be culturally adapted, following a rigorous process, to ensure that their translation will be equivalent to the original version both in its linguistic and cultural dimensions [14]. Such adaptations of the Delphi DOLBaPP definitions have been achieved in Spanish [15] and German [16] and several adaptations in other languages are in progress. However, to our knowledge, no cross-cultural adaptation of the Delphi DOLBaPP definitions in French has yet been made. The aim of this article is to present the process of cross-cultural adaptation of the Delphi DOLBaPP definitions in Quebec French and their pre-test among French-speaking adults in Quebec.

\section{Materials and methods}

The cross-cultural adaptation of the Delphi DOLBaPP questionnaires in French was conducted according to the "backward translation approach", which remains the most common and is considered the preferred approach by many researchers [17-19]. The method and guidelines provided in the "Guidelines for the process of cross-cultural adaptation of self-report measures" proposed by Beaton et al. [14], that were specifically adapted for the Delphi DOLBaPP definitions and questionnaires, were used. The following steps were followed:

Step 1: Initially, three translators who had French for mother tongue independently translated the Delphi DOLBaPP optimal questionnaire from English into French. The three translators had various experiences in translation. Two of them were student translators, who received formal supervision by professional translators. The third translator was a research professional without formal training in translation but with professional experience in health research and in translation of health-related scientific material and questionnaires.

Step 2: The study coordinator (SP) compared the individual French translations and prepared a synthesis version; the discrepancies identified between the different translations were discussed with the first author of the definitions (CED) [10]. At the end of this exercise, new proposals for the translation of the problematic elements were prepared and submitted to the three translators. Their comments enriched the discussions 
and led to a consensual French version. In case of disagreement between the translators, the final decision was taken by the main author (CED) of the DOLBaPP on the proposal of the coordinator of the study (SP).

Step 3: Two other translators, whose mother tongue was English, translated this French version back into English. They proceeded independently and without reference to the original English version of the questionnaire. The two backward translators were professional translators. The first one was a freelancer and the second one was working for a translation firm; English was their native tongue.

Step 4: It was at this stage that an expert committee, made up of the main authors of the original English version of the DOLBaPP (CED, KD, PRC) [10], musculoskeletal epidemiology specialists, and the coordinator of the cultural adaptation in French (SP), was formed to resolve all problematic translation issues in a consensual manner. In case of disagreement between the translators, the final decision was taken by CED on the proposal of SP. A pre-final version of the questionnaire in French was produced at the end of this step.

Step 5: In order to pre-test the French version of the questionnaire, it was self-administered to adults who were recruited among participants in the third data collection phase of the PROspective Quebec Study on Work and Health [20], a 24-year cohort study conducted among 9,188 white collar workers aged 18 years or older in the Quebec City area ("the cohort study"). In this step, according to the method proposed by Beaton et al. [14], the adaptation should be applied to a sample of at least 30 to 40 participants. In the current study, since access was provided to a large group of the cohort study, a larger convenience sample was selected. During five weeks, the first two participants of the cohort study who came to the Centre de recherche du CHU de Quebec-Université Laval for their follow-up meeting in the morning, and the first two who came in the afternoon were systematically selected for our study. They were asked to complete the Delphi DOLBaPP questionnaire and an evaluation form which concerned i) the time required to complete the questionnaire, ii) the wording of the questions, iii) the illustration used in the questionnaire, iv) the structure of the questionnaire and $v$ ) the length of the questionnaire. A research professional informed the participants about this additional task and explained it to them. If any selected morning or afternoon participant was over 70 years of age or had cognitive impairment (whether self-reported or according to his or her companion), he or she was replaced by the person appearing next in the appointment list of the cohort study. The participants were allowed to take the time they needed to complete the questionnaire and the evaluation form. The age criterion was applied so as not to increase the burden on the older participants, who generally needed more time to complete the full set of questionnaires of the cohort study. After they had completed the questionnaire and the evaluation form, the participants' comments on certain issues, words or phrases were also collected in the evaluation form and documented.

Data were analysed using SAS software version 9.4. The distribution of participants' characteristics and their responses to the questionnaire on LBP and to the evaluation form were described.

Qualitative analyses of the answers to the three open-ended questions in the evaluation form were carried out; a thematic content analysis was conducted on the basis of these answers [21]. The qualitative data focused on i) the assessment of the wording of the questions, ii) the conditions for completing the questionnaire, and iii) comments or suggestions for improving the questionnaire. Responses were codified and categories were constructed. For each category identified, its distribution was analyzed among the respondents.

\section{Results}

The result of the French translation of the questionnaire is shown in Table 1. The third column illustrates, in bold type, the changes that were made to the original English version of the questionnaire as a result of the standardized adaptation process. In questions one, three, five, six and seven, the words "in the past four weeks" were translated into French as "au cours des quatre dernières semaines", and then back-translated into English as "in the last four weeks". When asked about their choice, the English-speaking translators indicated that there was a slight difference in the meaning of "past" and "last" in English, and that the latter term was considered to correspond to the concept of "the latest, most recent", which they felt better matched the time reference specified in the question. The expert committee therefore decided to modify the original English version of the questionnaire by replacing "past" with "last". Taking into account the remarks of the 
French-speaking translators, who found that the words "report" and "feverish illness" (exclusions mentioned in question 1) were somewhat difficult to understand and translate into French, a proposal was made to reformulate "Please do not report pain from feverish illness or menstruation" as "Please do not take into account pain caused by menstruation or by an illness accompanied by fever". The two English-speaking translators also recommended the use of "lower" rather than "low" in the expression "pain in your lower back" (questions one and five), as "lower" sounds more idiomatic in English. These two questions of the original English version were therefore amended accordingly. In question four, the English translators found that the expression "go below" was more familiar than "spread below" to describe a pain that goes down the length of the leg, and that it would be easier for English-speaking respondents to understand. In addition, they also felt that "go below" was more consistent with the previous question ("Have you had pain that goes down the leg?").

Table 1. Results of the translation of the Delphi DOLBaPP questionnaire from English to French

\begin{tabular}{ll}
\hline No. Initial English version & $\begin{array}{l}\text { French version formulations as a result } \\
\text { of the translation process }\end{array}$ \\
\hline
\end{tabular}

1 In the past four weeks, have you had pain in your low back (in the area shown on the diagram)? Please do not report pain from feverish illness or menstruation.

Yes No

Au cours des quatre dernières semaines, avez-vous eu mal au bas du dos (dans la région illustrée sur le schéma)? Veuillez ne pas tenir compte d'une douleur due à une maladie accompagnée de fièvre ou aux menstruations.

\section{Oui Non}

2 If yes, was this pain bad enough to limit your usual activities or change your daily routine for more than one day?

Yes No

3 In the past four weeks, have you had pain that goes down the leg?

Yes No

4 If yes, has this pain spread below the knee?

Yes No

5 If you had pain in your low back in the past four weeks, how often did you have the pain?

- On some days

- On most days

- Every day

6 If you had low back pain in the past four weeks, how long was it since you had a whole month without any low back pain?

- Less than three months

- Three months or more but less than seven months

- Seven months or more but less than three years

- Three years and more
Si oui, la douleur était-elle assez forte pour limiter vos activités habituelles ou pour changer votre routine quotidienne pendant plus d'une journée?

$$
\text { Oui Non }
$$

Au cours des quatre dernières semaines, avez-vous eu une douleur qui descendait le long de votre jambe?

Oui Non

Si oui, est-ce que cette douleur descendait en bas du genou?

$$
\text { Oui Non }
$$

Si vous avez eu mal au bas du dos au cours des quatre dernières semaines, à quelle fréquence avez-vous eu mal?

\section{- Certains jours}

- La plupart des jours

- Tous les jours

Si vous avez eu mal au bas du dos au cours des quatre dernières semaines, depuis combien de temps aviez-vous passé un mois complet sans avoir aucune douleur au bas du dos?

- Moins de trois mois

- Trois mois ou plus mais moins de

- Sept mois ou plus mais moins de trois ans sept mois
Modifications of initial English version resulting from the adaptation process

In the last four weeks, have you had pain in your lower back (in the area shown on the diagram)? Please do not take into account pain caused by menstruation or by an illness accompanied by fever.

Yes No

In the last four weeks, have you had pain that goes down the leg?

Yes No

If yes, has this pain gone below the knee?

Yes No

If you had pain in your lower back in the last four weeks, how often did you have the pain?

- Some days

- Most days

- Every day

If you had low back pain in the last four weeks, how long was it since you had a whole month without any low back pain?

- Less than three months

- Three months or more but less than seven months

- Seven months or more but less than three years

- Three years or more

- Trois ans ou plus 
Table 1. Results of the translation of the Delphi DOLBaPP questionnaire from English to French (continued)

\begin{tabular}{|c|c|c|c|}
\hline No. & Initial English version & $\begin{array}{l}\text { French version formulations as a result } \\
\text { of the translation process }\end{array}$ & $\begin{array}{l}\text { Modifications of initial English version } \\
\text { resulting from the adaptation process }\end{array}$ \\
\hline \multirow[t]{2}{*}{7} & $\begin{array}{l}\text { If you had low back pain in the } \\
\text { past four weeks, please indicate } \\
\text { what was the usual intensity of } \\
\text { your pain on a scale of zero to } \\
10, \text { where zero means "no pain" } \\
\text { and } 10 \text { means "the worst pain } \\
\text { imaginable". }\end{array}$ & $\begin{array}{l}\text { Si vous avez eu mal au bas du dos au } \\
\text { cours des quatre dernières semaines, } \\
\text { veuillez indiquer quelle était l'intensité } \\
\text { habituelle de votre douleur sur une échelle } \\
\text { de zéro à } 10 \text {, où zéro veut dire «aucune } \\
\text { douleur» et } 10 \text { veut dire «la pire douleur } \\
\text { que vous puissiez imaginer». }\end{array}$ & $\begin{array}{l}\text { If you had low back pain in the last four } \\
\text { weeks, please indicate what was the } \\
\text { usual intensity of your pain on a scale } \\
\text { of zero to } 10, \text { where zero means "no } \\
\text { pain" and } 10 \text { means "the worst pain } \\
\text { imaginable". } \\
\text { No pain Worst pain }\end{array}$ \\
\hline & No pain Worst pain & Aucune douleur Pire douleur & \\
\hline
\end{tabular}

Changes are marked in bold in the third column

\section{Characteristics of participants}

In Table 2, the basic characteristics of the participants are presented. A total of 82 adults answered the Delphi DOLBaPP questionnaire and participated in its evaluation. They constituted a diverse population in terms of age, education level and marital status. More than half of them were women and the overwhelming majority were retired (90.2\%). Most of them had an annual income of 70,000 Canadian dollars (C\$) or more (54.9\%).

Table 2. Characteristics of participants

\begin{tabular}{llll}
\hline Characteristics & & $\boldsymbol{n}$ & Mean (standard deviation) or proportion (\%) \\
\hline Age in years & & 82 & $62.4(4.5)$ \\
Sex & Female & 50 & 61.0 \\
Education & Male & 32 & 39.0 \\
& < College degree & 25 & 30.5 \\
& College degree & 17 & 20.7 \\
Marital status & University degree & 40 & 48.8 \\
& Married & 24 & 29.3 \\
& Living in a common-law relationship & 28 & 34.2 \\
& Separated or divorced & 17 & 20.7 \\
Retired & Single & 8 & 9.8 \\
& Widower & 5 & 6.1 \\
& Yes & 74 & 90.2 \\
& No & 8 & 9.8 \\
& $<30.000$ & 4 & 4.9 \\
& $30-39,999$ & 9 & 11.0 \\
& $40-49,999$ & 5 & 6.1 \\
& $50-59,999$ & 10 & 12.1 \\
& $60-69,999$ & 9 & 11.0 \\
& $\geq 70,000$ & 45 & 54.9 \\
\hline
\end{tabular}

\section{Participants' answers to the Delphi DOLBaPP questionnaire}

No selected participants refused to complete the questionnaire and the evaluation form related to the adaptation study. According to the respondents' statements, 41 (50\%) had experienced LBP in the four weeks prior to the survey (Table 3). Of these, $10(24.4 \%)$ had had pain severe enough to have limited their usual activities for more than a day. In addition, 9.8\% of those who had had LBP in the last four weeks felt pain every day, while $73.2 \%$ said they felt pain only on some days. The intensity of LBP was reported to be fairly low ( $\leq 3$ out of 10 ) by more than half of the participants concerned $(60.0 \%)$. Of the 41 people who had had LBP in the last four weeks, only two had had severe pain ( $\geq 7$ out of 10 ). 
Table 3. Participants' answers to the Delphi DOLBaPP questionnaire

\begin{tabular}{|c|c|c|}
\hline Questions & $n$ & Proportion (\%) \\
\hline \multicolumn{3}{|c|}{$\begin{array}{l}\text { In the last four weeks, have you had pain in your lower back (in the area shown on the } \\
\text { diagram)? Please do not take into account pain caused by menstruation or by an illness } \\
\text { accompanied by fever. }\end{array}$} \\
\hline Yes & 41 & 50.0 \\
\hline No & 41 & 50.0 \\
\hline \multicolumn{3}{|c|}{$\begin{array}{l}\text { If yes, was this pain bad enough to limit your usual activities or change your daily routine } \\
\text { for more than one day? }\end{array}$} \\
\hline Yes & 10 & 24.4 \\
\hline No & 31 & 75.6 \\
\hline \multicolumn{3}{|c|}{ In the last four weeks, have you had pain that goes down the leg? } \\
\hline Yes & 19 & 23.2 \\
\hline No & 63 & 76.8 \\
\hline \multicolumn{3}{|l|}{ If yes, has this pain gone below the knee? } \\
\hline Yes & 14 & 73.7 \\
\hline No & 5 & 26.3 \\
\hline \multicolumn{3}{|c|}{ If you had pain in your lower back in the last four weeks, how often did you have the pain? } \\
\hline Some days & 30 & 73.2 \\
\hline Most of the days & 7 & 17.1 \\
\hline Every day & 4 & 9.8 \\
\hline \multicolumn{3}{|c|}{$\begin{array}{l}\text { If you had low back pain in the last four weeks, how long was it since you had a whole } \\
\text { month without any low back pain? }\end{array}$} \\
\hline Less than three months & 19 & 46.3 \\
\hline Three months or more, but less than seven months & 7 & 17.1 \\
\hline Seven months or more, but less than three years & 6 & 14.6 \\
\hline Three years or more & 9 & 22.0 \\
\hline \multicolumn{3}{|c|}{$\begin{array}{l}\text { If you had low back pain in the last four weeks, please indicate what was the usual intensity } \\
\text { of your pain on a scale of zero to } 10, \text { where } 0 \text { means "no pain" and } 10 \text { means "the worst } \\
\text { pain imaginable". }\end{array}$} \\
\hline$\leq 3$ & 24 & 60.0 \\
\hline 4 to 6 & 14 & 35.0 \\
\hline$\geq 7$ & 2 & 5.0 \\
\hline
\end{tabular}

\section{Participants' evaluation of the questionnaire}

Most of the issues addressed in the evaluation of the questionnaire on LBP showed high proportions of "Strongly agree" (Table 4). For three of the five questions (interesting subject, structure, and illustration), the proportion of "Strongly agree" was $80 \%$ or more. The other two aspects of the questionnaire (length and question wording) had proportions of "Strongly agree" of 79.3\% each. A high proportion of the participants $(89.0 \%)$ stated that it took them less than five minutes to complete the questionnaire while only $1.2 \%$ took more than 15 minutes. It should also be noted that $96.3 \%$ of the participants strongly agreed that the diagram for question one ("In the last 4 weeks, have you had pain in your lower back (in the area shown in the diagram?") was easy to understand, compared to $3.7 \%$ who more or less agreed. On the other hand, only $20.7 \%$ more or less agreed that the wording of the questions was easy to understand and only $2.4 \%$ disagreed that the structure of the questionnaire was clear and well done.

Table 4. Evaluation of the Delphi DOLBaPP questionnaire by the participants

\begin{tabular}{lll}
\hline Variables & $\boldsymbol{n}$ & Proportion (\%) \\
\hline Time to complete the questionnaire & & \\
Less than 5 minutes & 73 & 89.0 \\
Around 5 to 10 minutes & 8 & 9.8 \\
Around 10 to 15 minutes & 0 & 0.0 \\
More than 15 minutes & 1 & 1.2 \\
\hline
\end{tabular}


Table 4. Evaluation of the Delphi DOLBaPP questionnaire by the participants (continued)

\begin{tabular}{|c|c|c|}
\hline Variables & $n$ & Proportion (\%) \\
\hline \multicolumn{3}{|c|}{ The subject of the questionnaire is interesting. } \\
\hline Strongly agree & 70 & 85.4 \\
\hline More or less agree & 12 & 14.6 \\
\hline Strongly disagree & 0 & 0.0 \\
\hline \multicolumn{3}{|c|}{ The length of the questionnaire is appropriate. } \\
\hline Strongly agree & 65 & 79.3 \\
\hline More or less agree & 14 & 17.1 \\
\hline Strongly disagree & 0 & 0.0 \\
\hline Missing data & 3 & 3.7 \\
\hline \multicolumn{3}{|c|}{ The wording of the questions is easy to understand. } \\
\hline Strongly agree & 65 & 79.3 \\
\hline More or less agree & 17 & 20.7 \\
\hline Strongly disagree & 0 & 0.0 \\
\hline \multicolumn{3}{|c|}{ The illustration accompanying question 1 is easy to understand. } \\
\hline Strongly agree & 79 & 96.3 \\
\hline More or less agree & 3 & 3.7 \\
\hline Strongly disagree & 0 & 0.0 \\
\hline \multicolumn{3}{|c|}{ The structure of the questionnaire is clear and appropriate. } \\
\hline Strongly agree & 66 & 80.5 \\
\hline More or less agree & 13 & 15.9 \\
\hline Strongly disagree & 2 & 2.4 \\
\hline Missing data & 1 & 1.2 \\
\hline
\end{tabular}

\section{Qualitative analyses}

The final Delphi DOLBaPP questionnaire in French is presented in Figure S1. Overall, more than $62 \%$ of the participants did not find any poorly worded or confusing questions. About $9 \%$ of the participants found question six, which dealt with the duration of LBP, rather difficult to understand, as illustrated by the following statement: "Question six is quite difficult to understand. The references to time in the question and in the answer, as well as the negation (no pain), require careful thought to grasp the meaning and intention of this question". Two participants felt that the choice of answers to the question on the frequency of LBP (question five) was not very adequate. They suggested quantifying the number of days instead of saying "some days" ("certains jours"), which they felt was too vague.

About $61 \%$ of the respondents found that the Delphi DOLBaPP questionnaire was complete and that no important item was missing in the questionnaire. However, more than $18 \%$ thought it would be good to include items related to the causes of LBP. A smaller proportion (5\%) suggested to add questions on medication and to extend the questionnaire so as to cover the whole spine instead of just the lower back.

Finally, almost $90 \%$ of respondents did not make any comment or suggestion about the Delphi DOLBaPP questionnaire. Among suggestions, the main one concerned the additions of filters to facilitate the understanding of some questions. For example: if the answer to question one is "no", skip question two and go to question three.

\section{Discussion}

The use of reliable and valid measures in research is essential to provide evidence-based health care [22]. The standardized adaptation process used in the study reported here made it possible to adapt the Delphi DOLBaPP questionnaire specifically for francophones, while preserving the content and structure of the original version. The fact that the process included a backward translation step ensured that the meaning of the items was maintained between the English and French versions. Moreover, the standardized adaptation process of the Delphi DOLBaPP questionnaire into French resulted in minor changes following the backward 
translation. While these minor changes did not alter the meaning of the questions in the original version, the proposed rewording of certain words or phrases not only improved the translation and understanding of the French questionnaire, but also contributed to improving the original instrument. This is the case, for example, for "Please do not take into account pain caused by menstruation or by an illness accompanied by fever", which was included in the English original version after the back-translation step because of comments made by the French translators about the difficulty to understand and translate this sentence.

The results of this study are in line with the German adaptation of the DOLBaPP questionnaire, which also resulted in only minor modifications [16]. Some problems of conceptual equivalency were common to both the French and German translations, namely about the expression "having pain in your lower back". However, the reactions of participants were not always the same in both languages. During the French translation process, it was suggested that "go below the knee" ("descendre au bas du genou") replace "spread below the knee" in the original version, as this term was found to be the best match for the French translation. In the same version, the German translators suggested using the word "radiate" instead of "spread" or "go" for the same expression, as this word best represented the original construct when translated into German [16]. The question about duration of low back pain was found difficult to understand by some participants, both French and German. However, the French translators proposed a minor change to this question, with the exception of a modification to the last response choice "three years and more", which was replaced by "three years or more" ("trois ans ou plus"), while German translators proposed a change to make the question easier to understand: replacing the phrase "how long was it since you had" with "when was the last time that you had" [16]. This kind of exercise (cultural adaptation between two languages) usually presents these types of translation difficulties encountered in previous studies [23-26].

The overall assessment of the Delphi DOLBaPP questionnaire by the participants was rather positive. Overall, more than $62 \%$ of the participants did not find any poorly worded or confusing questions. Many had an excellent appreciation of the diagram illustrating the lumbar region included in the questionnaire. While Leonhardt et al. [16] found that $95 \%$ of the respondents took less than five minutes to complete the questionnaire, in our study this proportion was $89.0 \%$. The difference between these two results could perhaps be explained by the fact that the participants in Leonhardt et al.'s study were younger than those in our sample. In addition, some participants who had a reserved or negative assessment of certain questions, such as the question on the frequency of low back pain, may have had a problem of understanding the whole questionnaire. These participants wanted to integrate filters into the questionnaire to facilitate their understanding.

The prevalence estimates of LBP in the German and French versions are very similar. In both studies, they reached about $50 \%$ of the sample. The fact that these two prevalence estimates are comparable may be due to the use of the standardised definitions of LBP in the two studies. Other studies that have assessed the prevalence of LBP in white-collar workers using other definitions showed lower or slightly higher prevalence than the one that was found in the current study $[27,28]$, hence it is important to continue to promote the Delphi DOLBaPP definitions, as well as their cultural adaptation in other languages, and to work on their continuous improvement.

The choice of asking for three translations of the definitions from English to French instead of two represents an advantage in that it enabled to achieve a better consensus when necessary. Proceeding with a backward translation approach and the large number of participants who pre-tested the questionnaire in this study are strengths for the cultural adaptation method that was retained for this study.

For this pre-test, a representative sample was not chosen because it is not a recommendation for this kind of exercise. However, a possible limitation of this study is the fact that the participants were younger than the general population of LBP patients, which may have led to an overestimation of the understanding of the questionnaire among people aged 70 and over. In addition, white-collar workers are less at risk of LBP than blue-collar workers, and retired white-collar workers are not necessarily representative of the general population of LBP patients. 
This study ended up in the successful production of a valuable French translation of the Delphi DOLBaPP questionnaire adapted for the Quebec cultural context. This statement is based on the results of the pre-test with the sample. This French version of the questionnaire can now be used, with eventual minor adjustments if judged necessary, in other French-speaking countries such as France, Belgium, Switzerland, Luxembourg and French-speaking African countries. Populations from these countries will then be able to contribute to the standardization efforts that this questionnaire allows in order to improve the quality of LBP studies, as well as to share the benefits that derive from its use. Future cross-cultural adaptation of the Delphi DOLBaPP in other languages is needed to improve a better use of these standardized definitions.

The cross-cultural adaptation procedure used in this study is based on the Guide for the intercultural adaptation of the standardized definitions of Delphi low back pain, which itself takes up on the method proposed by Beaton et al. [14]. This specific guide, which is available upon request, proposes the application of a standardized translation method and provides all the necessary information for adapting the Delphi DOLBaPP definitions from English into another language.

\section{Abbreviations}

DOLBaPP: Definitions of Low Back Pain Prevalence

LBP: low back pain

\section{Supplementary materials}

The supplementary material for this article is available at: https://www.explorationpub.com/uploads/ Article/file/100165_sup_1.pdf.

\section{Declarations}

\section{Acknowledgments}

We thank Dr. Chantal Brisson for making it possible to conduct this study within the cohort study known as The PROspective Quebec (PROQ) Study on Work and Health. We also thank Dr. Manon Lévesque for coordinating the data collection and pre-test of the Delphi DOLBaPP questionnaire, for her availability to facilitate access to the data and for responding to our numerous requests, and finally we thank all the assistants who participated in the project.

\section{Author contributions}

CED initiated the study, SP coordinated the study, specifically the translation process and AL contributed to analyzing the data and wrote the first draft of the manuscript. All the authors discussed core ideas, participated in interpretation of data, and contributed to the writing of the final paper. All authors read and approved the submitted version.

\section{Conflicts of interest}

The authors declare that they have no conflicts of interest.

\section{Ethical approval}

This project was approved by the Ethics and Research Committee of the CHU de Quebec-Université Laval under the project number "2012-1674, DR-002-1409".

\section{Consent to participate}

Informed consent to participate in the study was obtained from all participants.

\section{Consent to publication}

Not applicable. 


\section{Availability of data and materials}

Data are available upon request to the corresponding author. The Delphi DOLBaPP definitions, questionnaires and cultural adaptations are available at http://backpaindefs.org.

\section{Funding}

Funding sources: Canadian Institutes of Health Research (CIHR) through funding of the PROspective Quebec (PROQ) Study on Work and Health (principal investigator: Dr Chantal Brisson). The funder had no role in study design, data collection and analysis, decision to publish, or preparation of the manuscript.

\section{Copyright}

(C) The Author(s) 2021.

\section{References}

1. Walker BF. The prevalence of low back pain: a systematic review of the literature from 1966 to 1998. J Spinal Disord. 2000;13:205-17.

2. Bell JA, Burnett A. Exercise for the primary, secondary and tertiary prevention of low back pain in the workplace: a systematic review. J Occup Rehabil. 2009;19:8-24.

3. Loney PL, Stratford PW. The prevalence of low back pain in adults: a methodological review of the literature. Phys Ther. 1999;79:384-96.

4. Hoy D, Bain C, Williams G, March L, Brooks P, Blyth F, et al. A systematic review of the global prevalence of low back pain. Arthritis Rheum. 2012;64:2028-37.

5. Maher C, Underwood M, Buchbinder R. Non-specific low back pain. Lancet. 2017;389:736-47.

6. Scott NA, Moga C, Harstall C. Managing low back pain in the primary care setting: the know-do gap. Pain Res Manag. 2010;15:392-400.

7. Edwards J, Hayden J, Asbridge M, Gregoire B, Magee K. Prevalence of low back pain in emergency settings: a systematic review and meta-analysis. BMC Musculoskelet Disord. 2017;18:143.

8. Leboeuf-Yde C, Lauritsen JM. The prevalence of low back pain in the literature. A structured review of 26 Nordic studies from 1954 to 1993. Spine (Phila Pa 1976). 1995;20:2112-8.

9. Dionne CE, Dunn KM, Croft PR. Does back pain prevalence really decrease with increasing age? A systematic review. Age ageing. 2006;35:229-34.

10. Dionne CE, Dunn KM, Croft PR, Nachemson AL, Buchbinder R, Walker BF, et al. A consensus approach toward the standardization of back pain definitions for use in prevalence studies. Spine (Phila Pa 1976). 2008;33:95-103.

11. Hasson F, Keeney S, McKenna H. Research guidelines for the Delphi survey technique. J Adv Nurs. 2000;32:1008-15.

12. Powell C. The Delphi technique: myths and realities. J Adv Nurs. 2003;41:376-82.

13. Linstone HA, Turoff M. The Delphi method: techniques and applications. Boston: Addison-Wesley Publishing Company; 1975.

14. Beaton DE, Bombardier C, Guillemin F, Ferraz MB. Guidelines for the process of cross-cultural adaptation of self-report measures. Spine (Phila Pa 1976). 2000;25:3186-91.

15. CUESTIONARIO DELPHI DOLBaPP (versión española-España) [Internet]. Kovacs FM, Gestoso M, Mufraggi N, Martín M, Carretero D, Ferrer M, et al. 2010 [cited 2021 Nov 23]. Available from: https:// www.backpaindefs.org/PDF/Page_OptimalQ_Model_3_Spa.pdf

16. Leonhardt M, Liebers F, Dionne CE, Latza U. Cross-cultural adaptation of the delphi definitions of low back pain prevalence (German DOLBaPP). BMC Musculoskelet Disord. 2014;15:397.

17. Hilton A, Skrutkowski M. Translating instruments into other languages: development and testing processes. Cancer Nurs. 2002;25:1-7. 
18. Duffy ME. Translating instruments into other languages: basic considerations. Clin Nurse Spec. 2006;20:225-6.

19. Vallerand RJ. Vers une méthode de validation trans-culturelle des questionnaires psychologiques: implications pour la recherche en langue française. Psychologie Canadienne. 1989;30:662-80.

20. Trudel X, Gilbert-Ouimet M, Milot A, Duchaine CS, Vezina M, Laurin D, et al. Cohort profile: The PROspective Quebec (PROQ) study on work and health. Int J Epidemiol. 2018;47:693-i.

21. Miles M, Huberman AM. Qualitative data analysis. 2nd ed. Thousand Oaks: Sage Publications; 1994.

22. Rivelsrud MC, Kirmess M, Hartelius L. Cultural adaptation and validation of the Norwegian version of the swallowing quality of life questionnaire (SWAL-QOL). Health Qual Life Outcomes. 2019;17:179.

23. Girard MP, Marchand AA, Stuge B, Ruchat SM, Descarreaux M. Cross-cultural adaptation of the Pelvic Girdle Questionnaire for the French-Canadian population. J Manipulative Physiol Ther. 2016;39:494-9.

24. Parent-Vachon M, Parnell LKS, Rachelska G, Lasalle L, Nedelec B. Cross-cultural adaptation and validation of the Questionnaire for Pruritus Assessment for use in the French Canadian burn survivor population. Burns. 2008;34:71-92.

25. Denis I, Fortin L. Development of a French-Canadian version of the Oswestry Disability Index: cross-cultural adaptation and validation. Spine. 2012;37:E439-44.

26. Mak S, Soicher JE, Mayo NE, Wood-Dauphinee S, Bourbeau J. Cross-cultural adaptation of the CHAMPS Questionnaire in French Canadians with COPD. Can Respir J. 2016;2016:9304505.

27. Janwantanakul P, Pensri P, Moolkay P, Jiamjarasrangsi W. Development of a risk score for low back pain in office workers - a cross-sectional study. BMC Musculoskelet Disord. 2011;12:23.

28. Damanhuri Z, Zulkifli A, Lau ACT, Zainuddin H. Low back pain among office workers in a public university in Malaysia. Int J Public Health Clin Sci. 2014;1:99-108. 